\title{
Tap Water versus Bottled Water: A Pilot Study
}

\author{
Ryan Knox ${ }^{1}$, Rodney McDermott ${ }^{2}$ \\ ${ }^{1}$ Northern Ireland Water, Westland House, Belfast, Northern Ireland \\ ${ }^{2}$ Belfast School of Architecture and the Built Environment, Ulster University, Belfast, Northern Ireland \\ Email: r.mcdermott@ulster.ac.uk
}

How to cite this paper: Knox, R. and McDermott, R. (2019) Tap Water versus Bottled Water: A Pilot Study. Journal of Water Resource and Protection, 11, 1398-1407.

https://doi.org/10.4236/jwarp.2019.1111081

Received: September 16, 2019

Accepted: November 23, 2019

Published: November 26, 2019

Copyright $\odot 2019$ by author(s) and Scientific Research Publishing Inc. This work is licensed under the Creative Commons Attribution International License (CC BY 4.0).

http://creativecommons.org/licenses/by/4.0/

\begin{abstract}
The aim of this exploratory research and comparative numerical pilot study was to investigate any significant differences in the microbiological content of tap and bottled water through the measurement of risk indicator parameters including Enterococci, Escherichia coli (E. coli) and colony-forming units (CFUs). This study to investigate storage conditions and compare consumer options of public water supply and bottled water using microbiological limits was carried out for public health research. This was a unique pilot study to Northern Ireland with global relevance due to the increase in the bottled water market and the need to address the lack of consumer awareness regarding storage and microbiological content. No E. coli or Enterococci were found in any of the 31 tap or bottled water samples. Three unrefrigerated bottled water samples exceeded the threshold in Colony Counts $22^{\circ} \mathrm{C} \& 37^{\circ} \mathrm{C}$ (degrees Celsius) and failed in line with Drinking Water Directive guidelines. This indicated a link between storage conditions and microbiological quality. No link between prices or microbiological quality was indicated. This research recommends the creation of a regulator for the bottled water industry, the need for clearly labelled microbiological content and daily testing. Water suppliers such as Northern Ireland (NI) Water should promote the quality of tap water. Recommendations are also outlined for consumers. There is no statistically significant difference in the microbiological quality of tap and bottled water in Northern Ireland despite marketing claims.
\end{abstract}

\section{Keywords}

Water, Tap, Bottled, Public Health, Storage, Microbiological, Regulation

\section{Introduction}

This exploratory research study arose from the water industry in the field of public health engineering. The study was developed in response to the global in- 
crease in the bottled water market and consumer awareness of the microbiological content of potable water is raised. Through a unique comparative numerical pilot study, it was determined if storage conditions affected any significant microbiological differences between tap water and bottled water in Northern Ireland, see Figure 1.

Conflicting evidence exists between the bottled water industry marketing strategies and water samples analyses. European Union (EU) Drinking Water Directive 80/778/EEC (European Economic Community) states risk indicator parameter limits which are contradictory with test results. Awareness of proper storage techniques and microbiological content of potable water must be raised so that consumers can make an informed decision and safe choice regarding drinking water. Existing knowledge was deemed insufficient providing a valid rationale for this research.

\section{Literature Review Summary}

The Literature Review Summary evaluates critical points of current knowledge and methodological approaches. There is a current increase in the bottled water market as 2.6 billion litres are produced globally [2] with a predicted market value of $£ 50.24$ billion in 2017 [3]. Bottled water has benefits in that it is convenient, can be purchased almost anywhere and has a vital role to play in "the setting of emergencies or natural disasters" [4]. Consumers report of a preferred taste of bottled water or distaste for the public water supply.

Colony Counts at $22^{\circ} \mathrm{C}$ and $37^{\circ} \mathrm{C}$ are a "basic test for drinking water quality and give a reading for all bacteria present" [5]. A colony is defined as a group of bacteria from a single spore or cell. The acceptable values stated by EU Directive (2016) and World Health Organization (2011) drinking water quality guidelines are $100 / \mathrm{ml}$ (per millilitre) for Colony Counts $22^{\circ} \mathrm{C}$ and " $10 / \mathrm{ml}$ " for Colony Counts $37^{\circ} \mathrm{C}$ in bottled water [6] [7]. Pathogens in bottled water "should be a matter of significant concern in relation to public health" [8]. Exposure to a pathogen resulting in disease, depends upon "the dose and the immune status of the individual"

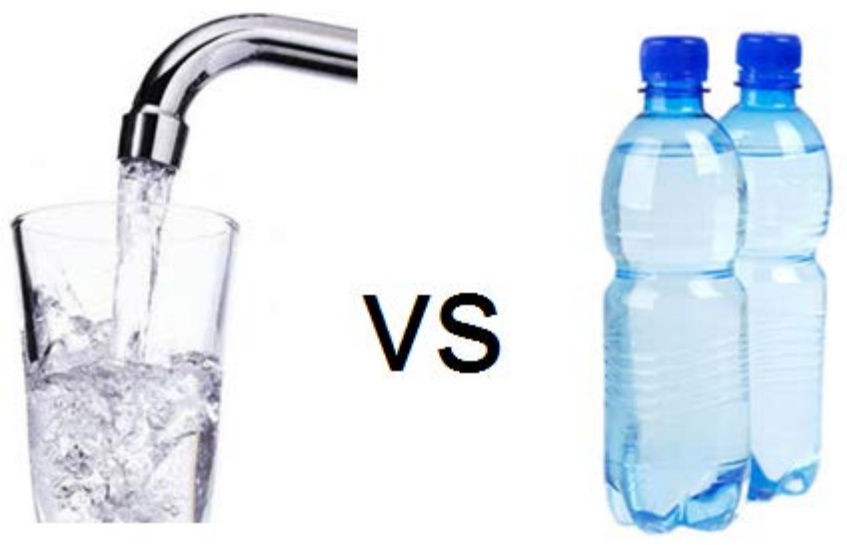

Figure 1. Tap water versus bottled water [1]. 
[7]. It is thought that consumers have been "bamboozled into thinking that all bottled water is pure and clean" [9]. United Kingdom (UK) tap water is recognised as "one of the best in the world" [10]. An example of a bottled water marketing strategy is, "perfect to keep you healthy" [11]. It has been found that "evidence for routine health risks or benefits from using bottled water is limited" [4].

The judgement from the literature was to continue with the aim of clarifying this situation. The literature review employed the funnel methodology (Global, UK \& Ireland and Element).

\section{Knowledge Gaps}

Gaps exist between scientific results and bottled water marketing strategies which have shifted consumer behaviour. There are inconclusive, varying test results from tap and bottled water research. This research aimed to assess the storage and microbiological makeup of potable water in Northern Ireland. Specific knowledge gaps were identified as follows.

- Consumer awareness of risk indicators potential presence in bottled water. These indicators (E. coli, Enterococci, CFUs and Cryptosporidium) pose a significant concern to public health.

- Testing requirements for tap and bottled water. “Ordinary tap water doesn't undergo as strict regulations as Natural Mineral Water" [11], which has proved to be untrue.

"Bottled variety is subject to far less stringent safety tests than tap water and is much more likely to be contaminated' [12]. Varying test results exist such as, "the bacterial counts in the bottled water samples ranged from less than 0.01 CFU/ ml to $4900 \mathrm{CFUs} / \mathrm{ml}$ (colony forming units per millilitre)". In contrast, tap water ranged from $0.2 \mathrm{CFU} / \mathrm{ml}$ to $2.7 \mathrm{CFUs} / \mathrm{ml}$ [13]. There are many straplines used to promote bottled water. For example, "You can count on bottled water when it comes to reliable, safe and consistent quality" [14]. However, in October 2019 , circa 23,000 bottles of water were withdrawn from sale in NI [15].

\section{Aim \& Objectives}

\subsection{Aim}

A quantitative pilot study was undertaken to investigate storage conditions and differences in the microbiological content of tap and bottled water in Northern Ireland.

\subsection{Study Objectives}

1) Research relevant literature using directed study to identify knowledge gap.

2) Gather samples from random brands and vendors for a diagonal slice of the market and varying storage conditions using an unbiased method for microbiological testing at NI Water's United Kingdom Accreditation Service (UKAS) ac- 
credited Westland laboratory.

3) Interpret empirical results featuring primary, quantitative data analysis whilst stating the applicability of conclusions.

4) Present the study aim and conclusions.

5) Make recommendations to the water industry (commercial and NI Water) arising from the results of the study.

\subsection{Null Hypothesis}

There is no statistically significant difference in the microbiological quality of tap and bottled water in Northern Ireland.

\section{Methodology}

Risk assessments were adhered to by employing key control measures such as Personal Protective Equipment. The funnel methodology was employed for literature search and review. Hazard and risk assessments, Control of Substances Hazardous to Health (COSHH) assessments and safety data sheets were all utilized in the collection and testing of samples. Tap and bottled water sampling were collected from across Northern Ireland. Samples were tested independently in the UKAS accredited Westland laboratory. A conflict of interest was avoided by restricting access by the authors to the laboratory and blind testing by laboratory staff i.e. unaware of brand, storage condition or origin of each sample. UKAS laboratories such as Westland assist in ensuring competency of testing and accuracy of data due to strict accreditation standards. Primary, quantitative data were collected and processed. Basic statistical analysis was carried out along with the compilation of process documentation. Further in-depth statistical analyses were conducted using the Statistical Package for the Social Sciences (SPSS) software. Digital illustration was adopted for the reporting of sample locations. Finally, a discussion of findings and recommendations were made to industry, governments and consumers.

\section{Sampling}

An unbiased method was devised listing towns and villages alphabetically and using random number generation to produce a large geographical spread (see Figure 2). A sample of 20 bottles of water (representing 16 brands) and 11 tap water samples were tested as part of this study. A variety of bottled water brands, sizes and vendors were used for a diagonal slice of the bottled water market. Samples were collected from across the country to obtain a representative sample of water available across Northern Ireland including the many rural communities. This method avoided testing only regional brands or reservoirs and assisted in randomising storage conditions. Bottled water on sale to the public was tested having been stored in vending machines, refrigerators, independent and chain stores. Samples were independently tested at NI Water's UKAS accredited Westland laboratory (see Figure 3). 


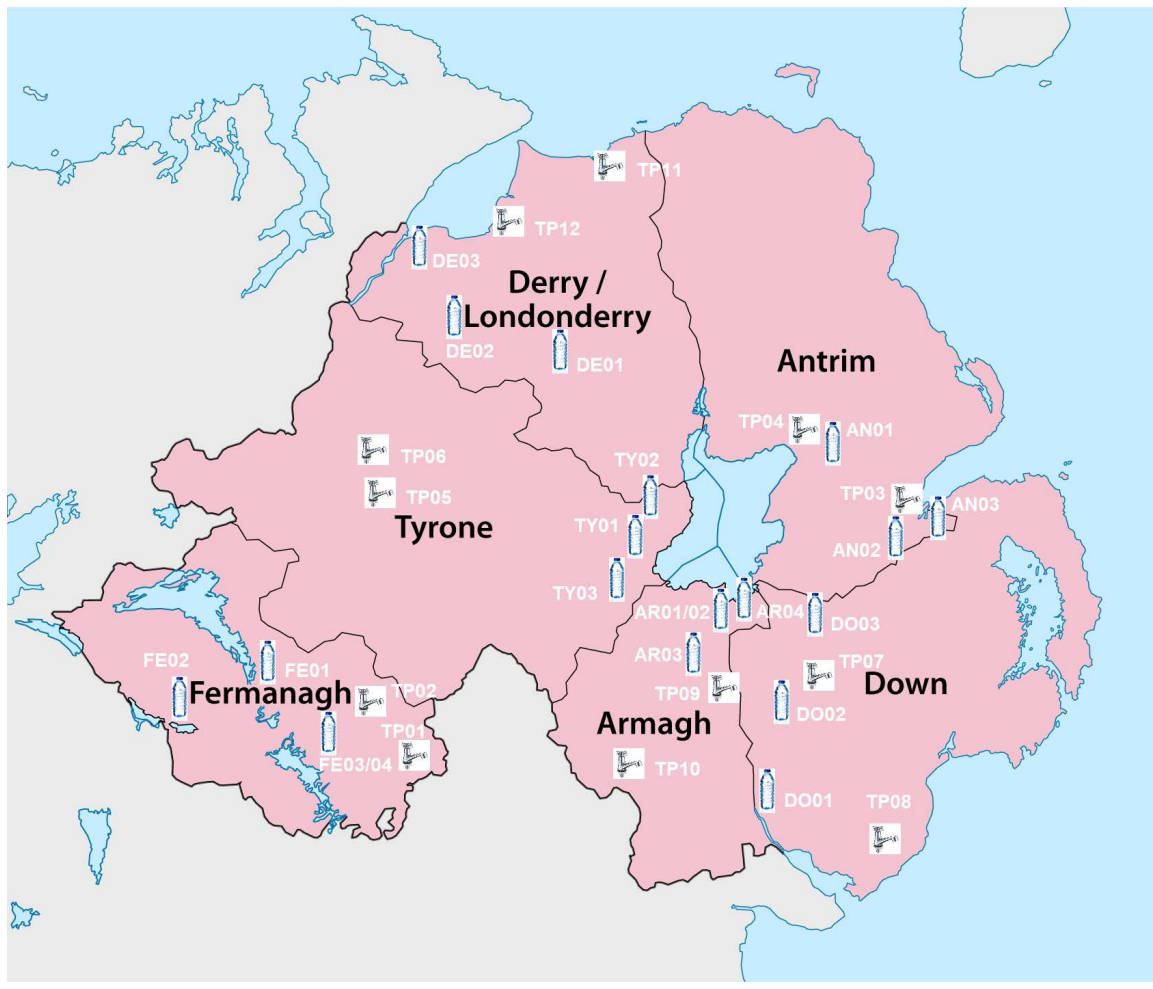

Figure 2. Northern Ireland sample map [16].

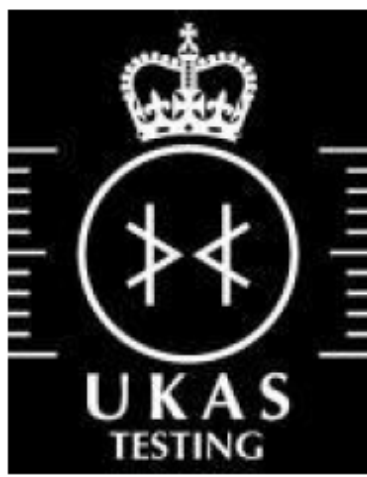

Figure 3. UKAS testing.

Samples were transported to the laboratory in a coolbox at $5^{\circ} \mathrm{C} \pm 3^{\circ} \mathrm{C}$. Bottled and tap water samples were collected under the same atmospheric conditions and delivered to the laboratory by 15:00 for the same day testing. A minimum of $500 \mathrm{ml}$ (millilitre) per sample was collected for the same day blind testing. A sample of $10 \%$ of bottled water samples were re-tested under supervision to ensure accuracy. The sample runs took place from the 27th February 2017 to the 3rd March 2017. A total of 12 reservoirs were randomly selected from 316 in service by random number generation. Tap water sample number five (TP05) from Killybrack 1 Service Reservoir (SR) result in County Tyrone is missing from the data set. This was due to the fact this reservoir was out of service that week for routine cleaning and inspection. Two tap water and three bottled water samples were 
collected by the first author from every county ensuring a backup was available. A total of 16 different brands of water were tested in order to reasonably represent the bottled water market in Northern Ireland.

\section{Results}

Colony Counts $22^{\circ} \mathrm{C}$ numbers per millilitre $(\mathrm{No} . / 1 \mathrm{ml})$ were greater for bottled water $($ Mean $(M)=19.15$, Standard Error $(S E)=12.93)$ than tap water $(\mathrm{M}=0$, $S E=0)$. This difference was not statistically significant $t(19.0)(t$-test), $p>0.05$; however, it did represent a medium-sized effect, $r=0.32$. Colony Counts $37^{\circ} \mathrm{C}$ (48 hours) (No./1 ml) were greater for bottled water $(M=1.40, S E=0.81)$ than tap water $(M=0.18, S E=0.18)$. This difference was not statistically significant $t$ (20.88), $p>0.05$ (probability value); however, it did represent a medium-sized effect, $r=0.31$.

On the basis of the statistical analysis, the null hypothesis can be accepted that there is no significant difference $(p=0.155)$ between the microbiological quality of tap and bottled water in Northern Ireland despite marketing claims; in fact, bottled water had higher Colony Counts which represented a medium-sized negative effect on its microbiological quality (see Figure 4 and Table 1). Tap water achieved $100 \%$ compliance with EU guidelines.

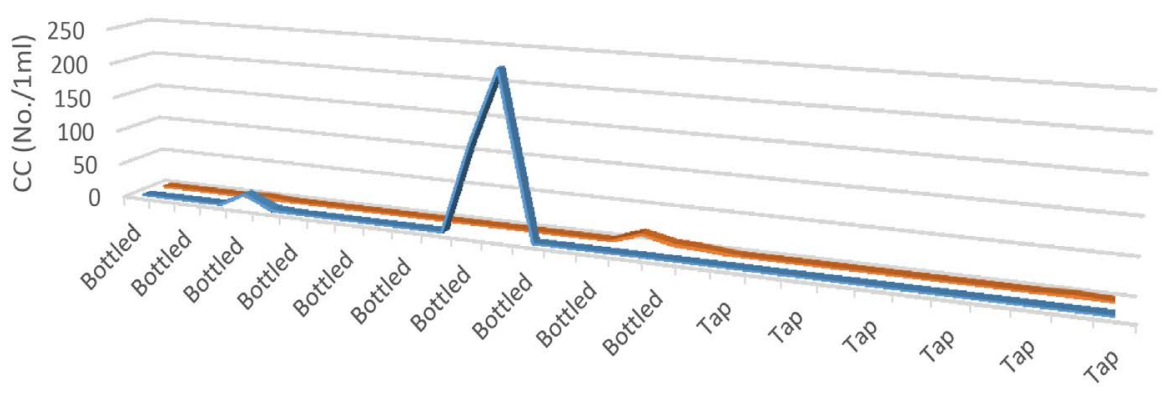

Sample Type

$$
\text { n Colony Counts } 22 \text { (No./1ml) Colony Counts } 37 \text { (No./1ml) }
$$

Figure 4. Samples colony counts $22^{\circ} \mathrm{C} \& 37^{\circ} \mathrm{C}$.

Table 1. Bottled water sample failures.

\begin{tabular}{ccc}
\hline Sample & Colony Count $22^{\circ} \mathrm{C}(\mathrm{No} . / 1 \mathrm{ml})$ & Colony Count $37^{\circ} \mathrm{C}(\mathrm{No} . / 1 \mathrm{ml})$ \\
\hline AR01 & 127 & 0 \\
AR02 & 233 & 0 \\
FE02 & 0 & 15 \\
EU Guideline $(/ 1 \mathrm{ml}):$ & 100 & 10 \\
\hline
\end{tabular}




\section{Conclusions}

Even though there is no statistically significant difference, it does not mean the medium sized effect is unimportant in practical terms. All three failing bottled water samples were stored in unrefrigerated, shelved conditions. The fact Colony Count was higher at $22^{\circ} \mathrm{C}$ than at $37^{\circ} \mathrm{C}$ indicates no direct link between temperature and microbiological quality.

The main conclusions drawn from this research were:

- Storage conditions of bottled water may pose a risk to microbiological quality (see Figure 5). This needs further investigation in a future study.

- No link was indicated between the price of water and microbiological quality.

- $15 \%$ of bottled water samples (3 of 20) failed to meet EU Drinking Water guidelines (see Figure 6).

- No E. coli or Enterococci risk indicators were found in any of the tested tap or bottled water samples.

- The results from this pilot study indicate that there is validity in carrying out a fullscale study.

- This pilot study has allowed important recommendations to be made.

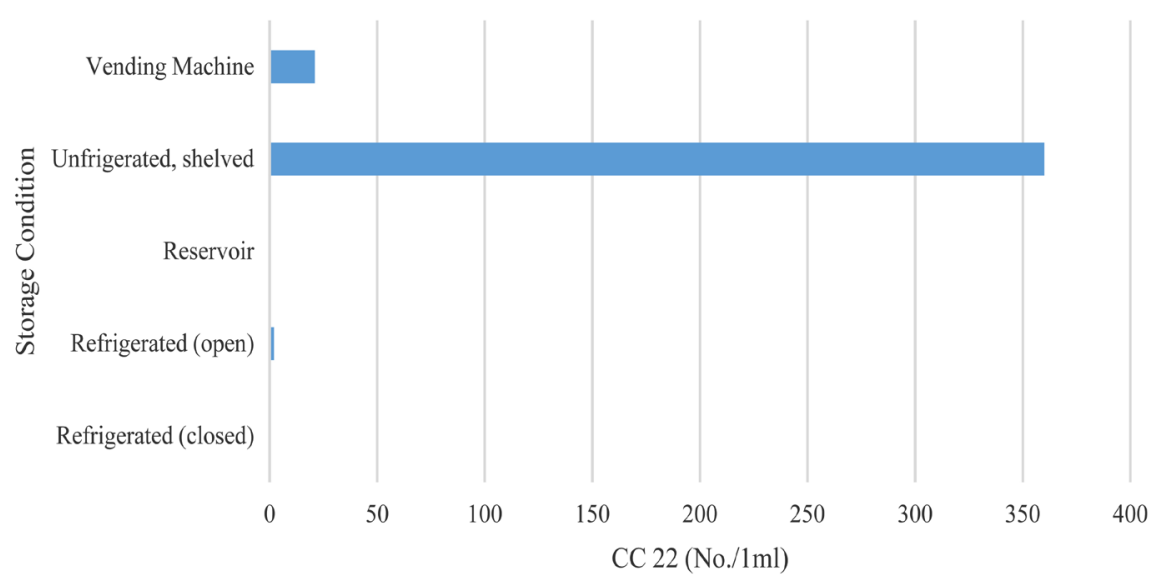

Figure 5. Sum of colony counts $22^{\circ} \mathrm{C}$ by storage condition.

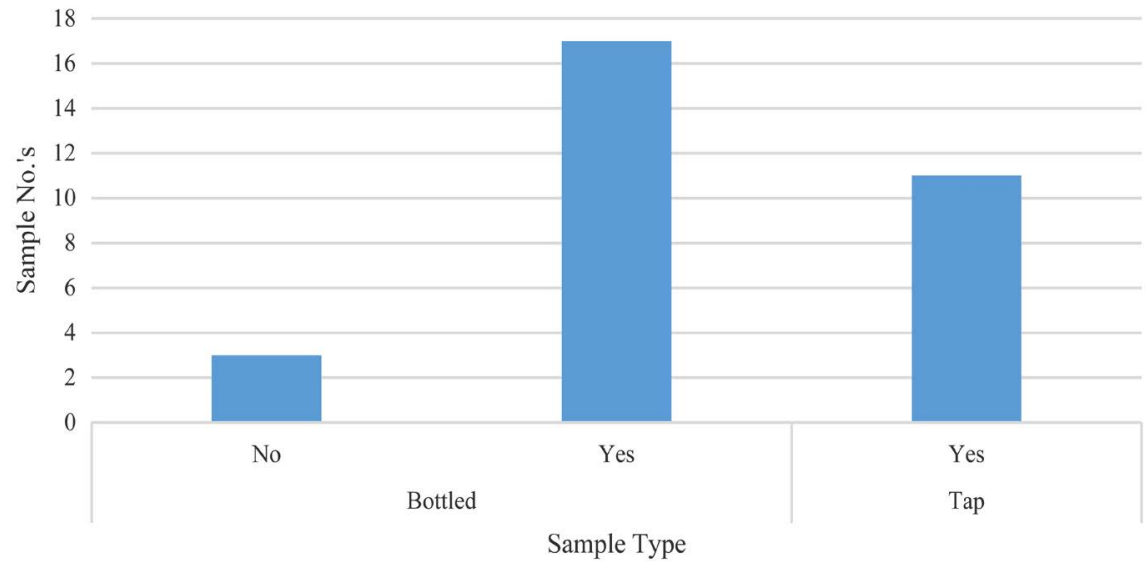

Figure 6. Count of compliant bottled and tap water samples. 


\section{Recommendations}

The results from this study clearly show that current NI regulations should be updated when considering bottled water. This finding is supported by other studies throughout the world. An Italian study reported the "need to update the current guidelines for drinking waters (including bottled waters) on the basis of epidemiological studies" [17]. The UK and Irish Government may need to review existing laws surrounding product labelling. Appropriate consumer safety warnings could be added to bottled water labels similar to that employed in food labelling.

Concerns also exist over the Polyethylene Terephthalate (PET) bottles, "because the plastic is porous you'll likely get a swill of harmful bacteria with each gulp if you reuse the bottles" [18]. Questions about the liquid contents of PET bottles and content trace elements over time are being raised [19]. Recommendations are made to the potable water industry, government and consumers as follows.

\subsection{Industry}

Daily testing of bottled water is recommended instead of the current minimum requirement of monthly testing. NI Water is raising awareness of water quality by challenging consumer perceptions. For example, the "Mourne" bottled brand filled straight from the tap [20]. Industry should consider recommending that retailers store bottled water in refrigeration units until point of purchase.

\subsection{Government}

Clear microbiological contents labels on bottled water, review of bottled water as food product and the creation of a bottled water regulator to oversee and enforce new guidelines. Labelling should include specific detail on the reuse of plastic bottles and appropriate storage advice. Results of on-site tests should be made public and guidelines enforced through penalties to ensure compliance.

\subsection{Consumer}

Clear government information and advice is required for consumers in Northern Ireland and beyond, especially those with impaired health. This advice should include summaries of compliance results for tap water and bottled water related to the Drinking Water Directive guidelines. Mid- to lower-price brands of bottled water performed as well as higher-price brands as no link between price and microbiological quality was indicated. If purchasing bottled water, collect from a closed refrigerator and store in the refrigerator. Avoid carrying bottled water around for the day as improper storage exposes the water to high temperatures from the sun.

It has also been found that "medical professions often recommend tap water over bottled water" [21]. Others describe the risk from bottled water as "unacceptable" [22]. When it comes to the water we drink, government and industry 
have an important role to play in reviewing and maintaining potable water standards and in protecting consumers through transparent information.

\section{Conflicts of Interest}

The authors declare no conflicts of interest regarding the publication of this paper.

\section{References}

[1] FiltersFast (2017) Bottled Water versus Tap Water. FiltersFast. http://www.filtersfast.com/articles/ArticleImages/bottled-water-vs-tap-water.jpg

[2] Zenith Global (2016) Reports and Data. http://www.zenithglobal.com/reports_data

[3] Research and Markets (2016) Global Bottled Water Industry. http://www.researchandmarkets.com/reports/2497307/global_bottled_water_indust ry

[4] Napier, G. and Kodner, C. (2008) Health Risks and Benefits of Bottled Water. Primary Care: Clinics in Office Practice, 35, 789-802. https://doi.org/10.1016/j.pop.2008.07.008

[5] Express Micro Science (2017) Drinking Water Tests. http://legionnaires-disease.com/Drinking\%20Water\%20Test.htm

[6] Official Journal of the European Community (2016) Drinking Water Directive Annex I 80/778/EEC. http://rod.eionet.europa.eu/instruments/218

[7] World Health Organization (2011) Guidelines for Drinking-Water Quality. http://www.who.int/water_sanitation_health/publications/2011/dwq_guidelines/en/

[8] Kerr, M. (2001) The Survival of Escherichia coli 0157: H7 in Natural Mineral Water. Ph.D. Thesis, Ulster University, Northern Ireland.

[9] Hinds, J. (2008) What's in Your Water?: The Shocking Truth about Bottled Water and Tap Water and How You Can Protect Yourself, J.A.H Enterprises.

[10] Tricker, R. (2009) Water Regulations in Brief. http://archbd.net/1elg.pdf

[11] Rocwell (2017) Benefits of Rocwell Water. https://www.rocwellwater.com/benefits-of-rocwell-water/

[12] Younger, P. (2013) Bottled Water "Not as Safe as Tap Variety". http://www.telegraph.co.uk/news/health/news/9775158/Bottled-water-not-as-safe-a s-tap-variety.html

[13] Ayres, L.W. and Lalumandier, J.A. (2000) Fluoride and Bacterial Content of Bottled Water vs. Tap Water. Archives of Family Medicine, 9, 246-250. https://doi.org/10.1001/archfami.9.3.246

[14] International Bottled Water Association (2017) The Healthy Choice. http://www.bottledwater.org/health

[15] BBC News Northern Ireland (2019). https://www.bbc.com/news/uk-northern-ireland-50172017

[16] Mappery (2017) Northern Ireland Geographical Sample Map, Mappery. http://www.mappery.com/maps/Northern-Ireland-General-Map.png

[17] Cidu, R., Frau, F. and Tore, P. (2011) Drinking Water Quality: Comparing Inorganic Components in Bottled Water and Italian Tap Water. Journal of Food Composition and Analysis, 24, 184-193. https://doi.org/10.1016/j.jfca.2010.08.005 
[18] Barclay, E. (2010) Why Tap Water Is Better than Bottled Water.

http://news.nationalgeographic.com/news/2010/03/100310/why-tap-water-is-better/

[19] Tukur, A. (2011) Antimony and Acetaldehyde Migration from Nigerian and British PET Bottles into Water and Soft Drinks under Typical Use Conditions: Concentration of Migrants and Some Trace Elements in Polyethylene Terephthalate and in Bottled Contents. Ph.D. Thesis, University of Bradford, Bradford.

[20] Northern Ireland Water (2017) Publications. http://www.niwater.com/publications/

[21] Majd, S. (2015) Should You Drink Tap or Bottled Water? https://www.scientificamerican.com/article/should-you-drink-tap-or-bottled-water/

[22] Pant, N.D., Poudyal, N. and Bhattacharya, S.K. (2016) Bacteriological quality of Bottled Drinking Water versus Municipal Tap Water in Dharan Municipality, Nepal. Journal of Health Population and Nutrition, 35, 17. https://doi.org/10.1186/s41043-016-0054-0 